\title{
Beware the baited hook of publicity
}

\section{Headlines are tempting but lead to disillusionment — and a sour taste with your spaghetti.}

Sir - In his Words essay "Good news is no news" (Nature 413, 113; 2001), John Emsley suggests that scientists who want their work featured in the media should learn how to package their discoveries by finding the right "hooks" for the public.

Scientists have various reasons for wanting to make headlines. Informing the public about the state of a scientific field or of a discovery; attracting funds to hospitals and universities; advertising companies with which they are involved; or (all-toocommon) self-aggrandizement - these are all valid reasons for talking about science. But they all should have the same common denominator: the truth.

Unfortunately, the media often embellish, sensationalize and exaggerate reality, which creates false illusions. I would advise caution in encouraging such behaviour. The danger is that a journalistic mentality could infiltrate even the scientific literature, as even prestigious journals can be guilty of publishing splashy and 'sexy' studies that are not scientifically sound.

My personal experience with the 'tabloidization' of scientific information began when I moved to Manhattan, and discovered some of the best Italian restaurants in the world. What does this have to do with science and media? A lot for me, as I have made friends with many Italian restaurateurs. Frequently, in the past few years, I have been approached by an Antonio, Giovanni or Marcello with "Have you seen it in the news?". "No, what?" I answer. "An Italian doctor has discovered a cure for cancer (or this or that)," is the reply.

It was in 1998 that I first learned that Luigi Di Bella, an 85-year-old practitioner in a small Italian town, had discovered a miraculous cure for cancer (see Nature 391, $217 ; 1998)$. The media had blown this up so much that the Italian parliament was forced to approve a clinical trial (see Nature 392, 421, 1998) to test the 'cure': a cocktail of somatostatin and vitamins. After months of testing, there was no evidence that it worked (see Nature 394, 514; 1998). Hundreds of patients may have suffered through not getting better treatment.

'Breakthroughs' are regularly announced by the most prestigious Italian newspapers, magazines and television channels. And many times, after yet another explosive report of a remarkable discovery, I have had to disillusion my restaurateur friends about the prospect of eternal youth and similar preposterous claims.

The tabloidesque Italian media have provided us with many entertaining evenings in New York City. Yet I am left with a bad taste in my mouth despite the excellent dinners I have enjoyed, as I am afraid that the Antonios, Giovannis and Marcellos, unable to distinguish which scientific information is correct and which isn't, will end up regarding all of it with scepticism. Is it really worth attracting a larger audience on one occasion, if the next time your credibility will be compromised? This is clearly a question for the media as

well as for those scientists who like to promote their discoveries.

Just a suggestion: if you are a scientist in Manhattan, don't make it evident in certain Italian restaurants. They might not take you seriously, and don't be surprised if they ask you to pay in cash ... Michele Pagano

Department of Pathology, New York University School of Medicine, 550 First Ave, New York, New York 10016, USA

\section{Industry and evaluation}

Sir - Despite the statement in your Opinion article "Finding a future for GM crops" (Nature 414, 1; 2001), the Supply Chain Initiative on Modified Agricultural Crops (SCIMAC) is not involved with coordination of farm-scale evaluations of genetically modified (GM) crops in Great Britain, nor has industry been involved in setting the questions or research agenda underlying the evaluations.

The research agenda was developed by the UK Department for Environment, Food and Rural Affairs (DEFRA) and the Scottish Executive, in response to concerns raised by English Nature and the Royal Society for the Protection of Birds (L. G. Firbank et al. Nature 399, 727-728; 1999). The research is conducted by contractors (Centre for Ecology and Hydrology, Institute of Arable Crops Research and the Scottish Crop Research Institute), fully funded by the UK government.

Evaluations are overseen by a steering committee of independent scientists. SCIMAC's role is to provide a pool of farms from which we scientists select our sample, and which is subject to approval by the steering committee. SCIMAC holds the contracts with the farmers to grow the crops, and is obliged to ensure compliance with the conditions for GM-plant release. SCIMAC has a limited role in providing advice to the farmers on use of herbicides on GM crops. SCIMAC's role is carefully limited, largely to have a clear division of responsibilities, but also because all parties involved agree that clear boundaries help to avoid any apparent conflict of interest, as your Opinion article stated.

The report by the Agriculture and Environment Biotechnology Commission to which you refer was supportive of the evaluations. Perhaps we scientists were not attacked by the commission precisely because the members appreciated the precautions that have been made to ensure the impartiality of the research.
These precautions are listed in the documentation (see www.defra.gov.uk/ environment/fse/index.htm).

Les Firbank

Farm-Scale Evaluations of GM Herbicide-tolerant Crops, Centre for Ecology and Hydrology, Merlewood Research Station, Grange-over-Sands, LA11 6JU, UK

We stand by our account - Editor, Nature.

\section{Dogs won more fame than female colleagues}

Sir - Your informative News Feature "Eyes on the prize" (Nature 413, 560-564; 2001) contains a photo of the Russian physiologist Ivan Pavlov, winner of the 1904 Nobel prize, with male colleagues and one of the dogs he used to discover the existence of the conditioned reflex.

Some years ago, I came across the original photograph, which also shows two women from Pavlov's team. One may have been Dr Maria Kapitonovna Petrova and the other Dr Maria Nikolayevna Yerofeyeva. Perhaps your readers may have definite information about their identity?

The existence of these women left on the cutting-room floor has been, like so many others, excised from history. Women scientists deserve better treatment today. Caroline L. Herzenberg 1700 E. 56th Street 2707, Chicago, Illinois 60637-5092, USA

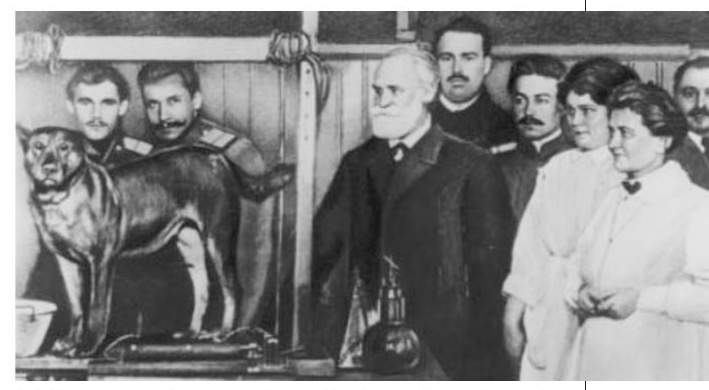

Full picture: female physiologists, thought to be M. K. Petrova and (far right) M. N. Yerofeyeva. 